\title{
Changes in oxygenation and pulmonary haemodynamics in preterm infants treated with inhaled nitric oxide
}

\author{
N V Subhedar, N J Shaw
}

\begin{abstract}
Aim-To investigate changes in various cardiorespiratory variables with inhaled nitric oxide (NO), as part of a randomised controlled trial.

Methods-Infants were treated with inhaled NO for 72 hours. Changes in oxygenation were assessed using the oxygenation index (OI). Serial changes in pulmonary artery pressure (PAP) were assessed using the Doppler derived acceleration time to right ventricular ejection time ratio (AT:RVET). Doppler measurements of right ventricular output, pulmonary blood flow, and systolic PAP was performed in a subset of infants.

Results-Twenty infants received inhaled NO and 22 acted as controls. Infants were treated at a median dose of 5 (range 5 to 20) ppm. There was a fall in median OI by $17 \%$ in treated infants within 30 minutes of treatment. The fall in OI in treated infants was significantly different from the response in controls until 96 hours. Infants treated with inhaled NO showed a rapid response with a median rise in AT:RVET of 0.04 (range -0.06 to 0.12 ) within 30 minutes. The change in AT:RVET was significantly different from controls until 4 hours. Median systolic PAP also fell in treated infants by 6.1 (range -14.4 to -4.4 ) $\mathrm{mm} \mathrm{Hg}$ within 1 hour. Changes in OI were significantly associated with changes in PBF ( $r=0.44)$, but not with changes in AT:RVET.

Conclusion-Treatment with inhaled NO rapidly improves oxygenation and lowers PAP in preterm infants. However, these effects are transient and treatment does not influence long term outcome. (Arch Dis Child 1997;77:F191-F197)
\end{abstract}

Institute of Child Health, University of Liverpool

$\mathrm{N}$ V Subhedar

Regional Neonatal Intensive Care Unit, Liverpool Women's

Hospital

N J Shaw

Correspondence to:

Dr N V Subhedar

Regional Neonatal Intensive

Care Unit,

Liverpool Women's Hospital,

Crown Street,

Liverpool

L8 7SS.

Accepted 1 July 1997 term infants and results in significant morbidity and mortality. Hypoxaemia in RDS is predominantly the result of intrapulmonary shunting and poor ventilation-perfusion matching. In some infants pulmonary hypertension with significant right to left extrapulmonary shunting may also contribute to arterial hypoxaemia. ${ }^{6} 7$ It has been suggested that the improvement in oxygenation with inhaled NO occurs through two principal mechanisms: (1) by lowering of pulmonary vascular resistance (PVR) and a reversal of extrapulmonary shunting through selective pulmonary vasodilation; and (2) by a redistribution of pulmonary blood flow (PBF) with enhanced ventilation-perfusion matching. ${ }^{8} 9$ Improved gas exchange in infants with RDS may help to minimise lung injury through a reduction in oxygen and ventilatory requirements.

Although several published case series have shown a short term effect for inhaled NO in improving arterial oxygenation, ${ }^{810-13}$ controlled trials confirming short and/or long term benefit have been reported only in term infants with PPHN. ${ }^{14-16}$ No published controlled trials have shown its efficacy in preterm infants. The aim of this study was to investigate changes in oxygenation, respiratory support, and pulmonary haemodynamics as part of an ongoing randomised controlled trial of inhaled NO in high risk preterm infants.

\section{Methods}

This study was performed as part of a trial of inhaled NO in preterm infants, ${ }^{17}$ and was approved by the local paediatric ethics committee. Preterm infants were considered eligible for entry into the trial at 96 hours of age if they fulfilled the high risk criteria determined by a chronic lung disease (CLD) score. ${ }^{18}$ Parental consent was sought as soon as possible once the infant had met the entry criteria. Infants were randomly assigned by factorial design into one of four treatment groups: (1) inhaled nitric oxide (group 1); (2) intravenous dexamethasone (group 2); (3) both treatments together (group 3); and (4) no new treatment (group 4). The aim of this study was to compare results in infants treated with inhaled NO (groups 1 and 3) with control infants (groups 2 and 4).

All infants were treated with two doses of artificial surfactant (ALEC, Britannia Pharmaceuticals), and those below $1 \mathrm{~kg}$ were treated with indomethacin, $0.1 \mathrm{mg} / \mathrm{kg} / \mathrm{dose}$ at intervals 
Table 1 Patient characteristics

\begin{tabular}{|c|c|c|c|c|}
\hline \multirow[b]{2}{*}{ Birthweight $(\mathrm{g})^{\star}$} & \multicolumn{2}{|c|}{$\begin{array}{l}\text { Nitric oxide } \\
(n=20)\end{array}$} & \multicolumn{2}{|c|}{ Controls $(n=22)$} \\
\hline & 882 & $(416-1354)$ & 750 & $(520-1400)$ \\
\hline \multirow{2}{*}{\multicolumn{5}{|c|}{$\begin{array}{l}\text { Gestational age } \\
\text { (weeks) }\end{array}$}} \\
\hline & 27 & $(24-30)$ & 27 & $(22-31)$ \\
\hline $\operatorname{Sex}(M: F)$ & $12: 8$ & & $5: 17$ & \\
\hline Multiple pregnancy & 7 & $(35 \%)$ & 6 & $(27 \%)$ \\
\hline Antenatal steroids & 16 & $(80 \%)$ & 18 & $(82 \%)$ \\
\hline Caesarean section & 15 & $(75 \%)$ & 11 & $(50 \%)$ \\
\hline Outborn & 6 & $(30 \%)$ & 7 & $(32 \%)$ \\
\hline \multicolumn{5}{|l|}{ Apgar score (5 } \\
\hline $\min )^{\star}$ & 8 & $(2-10)$ & 8 & $(3-10)$ \\
\hline PDA & 5 & $(25 \%)$ & 4 & $(19 \%)$ \\
\hline Pneumothorax & 5 & $(25 \%)$ & 3 & $(14 \%)$ \\
\hline \multicolumn{5}{|l|}{ IVH grade } \\
\hline 1 & 3 & $(15 \%)$ & 1 & $(5 \%)$ \\
\hline 2 & 8 & $(45 \%)$ & 10 & $(45 \%)$ \\
\hline CLD risk score & 0.77 & $(0.43-1.0)$ & 0.79 & $(0.27-0.98)$ \\
\hline Trial entry (hours) ${ }^{\star}$ & 99 & $(96-113)$ & 104 & $(96-120)$ \\
\hline
\end{tabular}

$\star$ Median (range).

of 12 hours, immediately after birth and for two further doses. Respiratory support and inspired oxygen concentration $\left(\mathrm{FIO}_{2}\right)$ were adjusted to maintain arterial blood gases within a range where $\mathrm{pH}$ was $7.30-7.45, \mathrm{PaO}_{2} 50-80$ $\mathrm{mmHg}$ and $\mathrm{PaCO}_{2} 40-50 \mathrm{mmHg}$. Arterial blood gas analysis was performed as a baseline and at 30 minutes, 1, 2, 4 and 24 hours after onset of treatment, and at least daily thereafter for the period of study.

Inhaled nitric oxide was administered over 72 hours. The details of inhaled NO administration and monitoring have been described before. ${ }^{17}$ Briefly, the starting dose of 20 parts per million (ppm) was weaned, in steps of 5 $\mathrm{ppm}$, to a minimum dose of $5 \mathrm{ppm}$ if a positive response had been achieved within the first two hours of treatment. A reduction in the oxygenation index $(\mathrm{OI}$; mean airway pressure $\times$ $\mathrm{FIO}_{2} \times 100 / \mathrm{PaO}_{2}$ ) of $25 \%$ or more, or in $\mathrm{FIO}_{2}$ of 0.10 or more in infants without arterial access, was considered to be a positive response. Treatment with inhaled NO was continued for 72 hours and then an attempt was made to wean or stop treatment. A deterioration (defined as increase in OI by $25 \%$, or in $\mathrm{FIO}_{2}$ of 0.10 or more) was an indication to return to the previous dose for a further 24 hours.

The observed response to treatment with inhaled NO was categorised and compared with that in control infants. Oxygenation index was used to describe changes in respiratory status because it enabled changes in arterial oxygenation to be assessed in relation to concurrent changes in ventilatory support. ${ }^{19}$ An infant, either treated or control, in whom there was a reduction in OI by $25 \%$ or more, or in $\mathrm{FIO}_{2}$ of 0.10 or more (compared with baseline values) within the first 2 hours of treatment was classified as an "early responder." Infants who met this criteria at 24 hours of age were "late responders." The latter group was further subdivided into two groups: (1) "sustained responders," defined as infants in whom an early response was maintained for 24 hours; and (2) "delayed responders," who had initially failed to respond to treatment, but then achieved a response by 24 hours.

ECHOCARDIOGRAPHIC EXAMINATION

Two dimensional and Doppler echocardiography was performed using one of two ultrasound systems. Initially, a system combining a $7.5 \mathrm{MHz}$ imaging transducer with a $5 \mathrm{MHz}$ pulsed wave Doppler was used (ATL Ultramark IV). Subsequently, a colour Doppler system with high pulse repetition frequency (HPRF) pulsed wave and a $2.2 \mathrm{MHz}$ steerable continuous wave Doppler became available (Vingmed CFM 725, Sonotron). Infants had an echocardiographic examination before entry to the trial, to exclude a structural cardiac defect. Subsequently examinations were performed simultaneously with arterial blood gas analyses. All examinations were performed by a single observer (NVS). Information from the echocardiographic examination was made available only if a clinically important patent ductus arteriosus (PDA) was suspected by the clinical staff.

Pulmonary artery pressure (PAP) was principally assessed using its inverse relation with the acceleration time to right ventricular time ration (AT:RVET) from the pulmonary artery Doppler velocity waveform, using pulsed wave Doppler. $^{20}$ Ductal patency haemodynamics were assessed from a high left parasternal view with the aid of HPRF and colour flow mapping. A left atrial to aortic roost (LA:Ao) ratio greater than 1.5 was used to identify left to right ductal shunting that was likely to be haemodynamically significant. ${ }^{21}$ Atrial shunting characteristics were assessed from a subcostal view.

In a subset of the study population, further studies of pulmonary haemodynamics were

Table 2 Changes in cardiorespiratory status with inhaled NO

\begin{tabular}{|c|c|c|c|c|c|c|}
\hline & \multicolumn{2}{|l|}{$M a p$} & \multicolumn{2}{|l|}{$\mathrm{FIO}_{2}$} & \multicolumn{2}{|l|}{$O I$} \\
\hline & Treated & Control & Treated & Control & Treated & Control \\
\hline 0 & $9(4-21)^{\star}$ & $7(3-12)$ & $0.45(0.22-1.0)$ & $0.37(0.21-0.72)$ & $7.9^{\star \star \star}(1.6-46.7)$ & $3.1(1.2-11.5)$ \\
\hline 30 minutes & $9(4-21)^{\star \star}$ & $7(3-12)$ & $0.36(0.21-1.0)$ & $0.37(0.21-0.72)$ & $6.3(1.2-45.7)$ & $3.2(1.2-16.6)$ \\
\hline 1 hour & $9(4-22)$ & $7(3-12)$ & $0.36(0.21-1.0)$ & $0.37(0.21-0.86)$ & $6.7(1.3-46.8)$ & $3.5(1.1-14.6)$ \\
\hline 2 hours & $9(4-19)$ & $6(3-12)$ & $0.38(0.21-1.0)$ & $0.33(0.21-0.78)$ & $5.4(1.3-39.6)$ & $3.0(1.4-14)$ \\
\hline 4 hours & $9(4-21)$ & $5(3-11)$ & $0.36(0.21-1.0)$ & $0.35(0.22-0.83)$ & $5.3(1.3-60.0)$ & $3.2(2.1-105)$ \\
\hline 24 hours & $7(0-21)$ & $5(0-13)$ & $0.41(0.21-1.0)$ & $0.31(0.21-0.88)$ & $6.0(1.5-28.8)$ & $5.0(1.1-11.3)$ \\
\hline 48 hours & $6(0-18)$ & $6(0-11)$ & $0.37(0.21-1.0)$ & $0.36(0.21-1.0)$ & $5.2(2.2-23.8)$ & $9.7(2.1-23.2)$ \\
\hline 72 hours & $6(0-21)$ & $6(0-12)$ & $0.37(0.21-1.0)$ & $0.32(0.21-1.0)$ & $4.4(1.6-46.7)$ & $4.1(1.2-23.5)$ \\
\hline 96 hours & $4(0-16)$ & $5(0-14)$ & $0.32(0.21-1.0)$ & $0.39(0.21-0.92)$ & $3.5(1.3-8.3)$ & $5.3(1.2-25.3)$ \\
\hline Day 7 & $0(0-11)$ & $5(0-11)$ & $0.30(0.21-0.88)$ & $0.35(0.21-0.77)$ & $9.5(6.7-15.1)$ & $5.6(2.9-12.2)$ \\
\hline
\end{tabular}

Values expressed as median (range).

MAP $=$ mean airway pressure $\left(\mathrm{cm} \mathrm{H}_{2} \mathrm{O}\right) ; \mathrm{FIO}_{2}=$ fractional inspired oxygen concentration; $\mathrm{PaCO}_{2}=$ arterial partial pressure of $\mathrm{CO}_{2}(\mathrm{~mm} \mathrm{Hg}) ; \mathrm{MBP}=$ mean arterial blood pressure $(\mathrm{mm} \mathrm{Hg})$.

${ }^{\star} \mathrm{p}=0.03$ vs controls; ${ }^{\star \star} \mathrm{p}=0.04$ vs controls; ${ }^{\star \star \star} \mathrm{p}=0.02$ vs controls. 


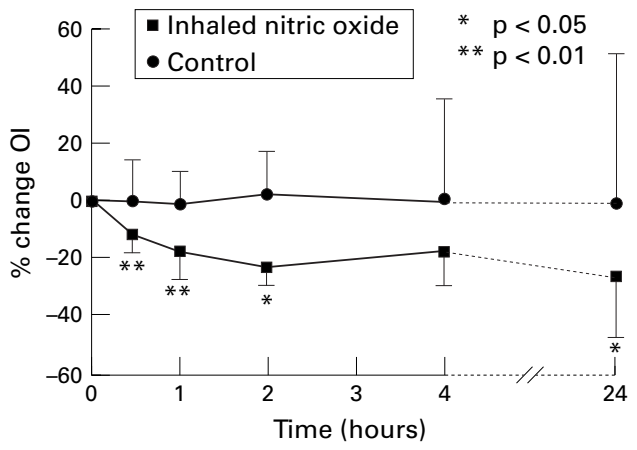

Data points represent medians (IQR)

Figure 1 Percentage change in OI with inhaled NO up to 24 hours

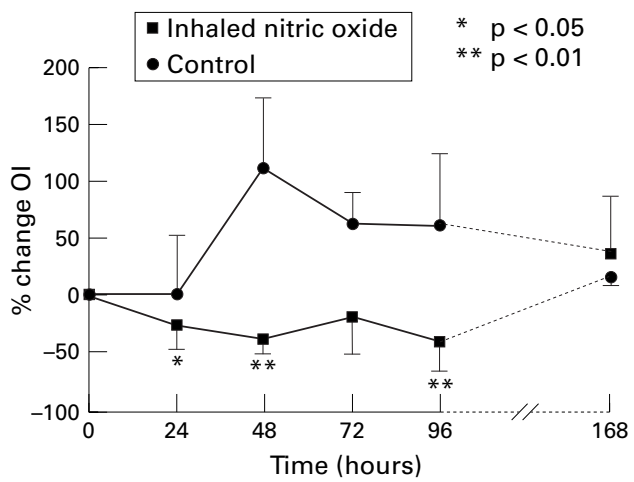

Data points represent medians (IQR)

Figure 2 Percentage change in OI with inhaled NO up to 168 hours

performed at the same time as AT:RVET was assessed.

\section{Systolic PAP}

Systolic PAP was estimated using the maximal velocity of tricuspid regurgitation. ${ }^{22}$ The echocardiographic examination was performed from various views to ensure measurement of maximal velocity. Colour Doppler was used initially to identify the presence or absence of tricuspid regurgitation, and the velocity of the tricuspid regurgitation jet was measured using either HPRF pulsed wave or steerable continuous wave Doppler. The pressure gradient between the right atrium and ventricle using the modified Bernoulli equation $\left(P=4 v^{2}\right.$, where $\mathrm{P}$ is the pressure gradient in $\mathrm{mm} \mathrm{Hg}$ and $\mathrm{v}$ is the velocity of the tricuspid regurgitation in metres/second. Systolic PAP can be calculated

Table 2 Continued

\begin{tabular}{|c|c|c|c|c|c|}
\hline \multicolumn{2}{|l|}{$\mathrm{PaCO}_{2}$} & \multicolumn{2}{|l|}{$M B P$} & \multicolumn{2}{|l|}{$A T: R V E T$} \\
\hline Treated & Control & Treated & Control & Treated & Control \\
\hline $49(28-74)$ & $44(25-68)$ & $34(29-48)$ & $41(30-50)$ & $0.28(0.16-0.41)$ & $0.30(0.20-0.45)$ \\
\hline $48(29-68)$ & $47(28-70)$ & $34(28-51)$ & $40(34-60)$ & $0.30(0.22-0.48)$ & $0.31(0.21-0.43)$ \\
\hline $48(27-69)$ & $46(31-59)$ & $40(25-55)$ & $40(31-57)$ & $0.31(0.18-0.46)$ & $0.29(0.12-0.38)$ \\
\hline $47(31-56)$ & $48(33-59)$ & $38(26-53)$ & $45(30-60)$ & $0.28(0.22-0.48)$ & $0.29(0.18-0.39)$ \\
\hline $45(26-68)$ & $45(34-66)$ & $40(30-46)$ & $40(32-54)$ & $0.30(0.18-0.43)$ & $0.28(0.21-0.4)$ \\
\hline $43(31-59)$ & $43(30-71)$ & $38(28-46)$ & $40(32-52)$ & $0.32(0.20-0.43)$ & $0.31(0.21-0.41)$ \\
\hline $48(29-53)$ & $43(28-94)$ & & & $0.32(0.20-0.41)$ & $0.31(0.20-0.41)$ \\
\hline \multirow[t]{3}{*}{49 (36-64) } & $43(29-95)$ & & & $0.30(0.18-0.39)$ & $0.29(0.24-0.41)$ \\
\hline & & & & $0.36(0.20-0.39)$ & $0.32(0.21-0.43)$ \\
\hline & & & & $0.29(0.26-0.34)$ & $0.34(0.25-0.45)$ \\
\hline
\end{tabular}

by adding an estimate of the right atrial pressure $(5 \mathrm{~mm} \mathrm{Hg}$ ) to this pressure gradient.

Right ventricular output

Serial changes in pulmonary artery minute distance were used as a measure of right ventricular output. ${ }^{23}$ This allowed the error present in the measurement of pulmonary artery diameter to be overcome, as stroke distance rather than stroke volume was calculated from the velocity time integral of the pulmonary artery flow velocity waveform with planimetry using integrated computer software. The mean value from five consecutive cardiac cycles was used. Heart rate was calculated from the R-R interval, from a simultaneous ECG tracing. Calculation of pulmonary artery minute distance was carried out by multiplying stroke distance $(\mathrm{cm})$ by heart rate (beats per minute). Within an individual subject, changes in pulmonary artery minute distance reflect changes in right ventricular output, assuming that pulmonary artery diameter remains unchanged. In infants with closed ductus arteriosus, changes in pulmonary artery minute distance reflect changes in pulmonary blood flow.

\section{STATISTICAL METHODS}

Results are presented as median (range). Changes in respiratory status were expressed as the percentage change in OI (to standardise for the wide variation in baseline OI). Differences between treatment and control groups were compared using the Mann-Whitney U test for continuous variables and the $\chi^{2}$ test or Fisher's exact test for categorical variables. The relation between changes in OI, AT:RVET, and pulmonary artery minute distance within individuals was analysed using analysis of covariance. ${ }^{24}$ Similarly, exclusion of infants with PDA allowed the relation between OI, AT:RVET, and pulmonary blood flow to be investigated. Data were analysed using SPSS statistical software (SPSS release 4.0).

\section{Results}

Forty two infants were randomly assigned in total: 20 infants received inhaled $\mathrm{NO}$ and 22 acted as controls. Patient characteristics before trial entry are shown in table 1. Although infants treated with inhaled NO had more severe respiratory disease before entry to the trial, with higher values of $\mathrm{FIO}_{2}$, OI, and mean airway pressure (MAP) compared with control infants (table 2), the overall risk score for CLD was similar in both groups.

After entry to the trial, $\mathrm{FIO}_{2}, \mathrm{PaCO}_{2}$, and mean systemic arterial pressure did not differ between the two groups (table 2). MAP was higher in the treated infants than in the controls until 30 minutes $(p=0.04)$. There was no difference in absolute OI in infants treated with inhaled NO compared with controls (except for baseline value). The subsequent reduction in OI was greater in treated infants compared with controls: within 30 minutes, median OI had fallen by $16.9 \%$ in treated infants ( $p<0.01$ vs control infants) (fig 1$)$. The reduction in OI was sustained for at least 96 
Table 3 Short term response with inhaled nitric oxide

\begin{tabular}{lccl}
\hline & Nitric oxide & Controls & $p$ Value \\
\hline Early responders & $13 / 20(65 \%)$ & $4 / 22(18 \%)$ & $<0.01$ \\
Late responders & $11 / 20(55 \%)$ & $6 / 22(27 \%)$ & 0.13 \\
$\quad$ Sustained responders & $7 / 13(54 \%)$ & $1 / 4(25 \%)$ & 0.66 \\
$\quad$ Delayed responders & $4 / 7(57 \%)$ & $5 / 18(28 \%)$ & 0.36 \\
Extubated within 24 hours & $4 / 20(20 \%)$ & $1 / 22(5 \%)$ & 0.29 \\
Died within 24 hours & $1 / 20(5 \%)$ & $1 / 22(5 \%)$ & 1.0 \\
\hline
\end{tabular}

Table 4 Baseline characteristics and outcome according to early response type

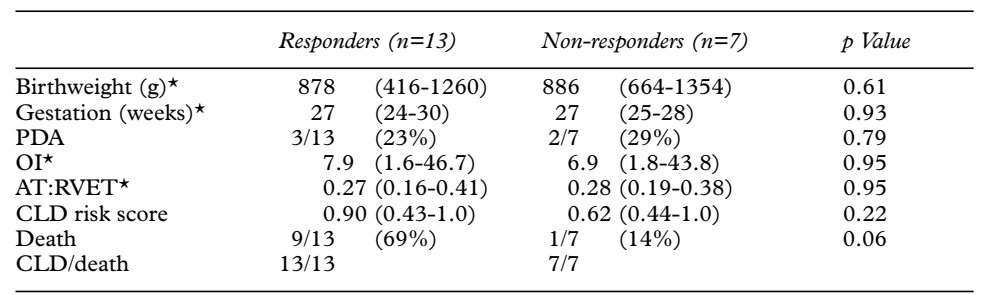

\footnotetext{
${ }^{\star}$ Median (range).
}

hours (fig 2). In contrast, OI was unchanged in control infants during the first 24 hours, and increased thereafter. By 168 hours there was no longer a significant difference in percentage change in OI between the two groups.Early responders were significantly more common in the treatment group (table 3). In all these infants the dose of inhaled NO was successfully weaned to $5 \mathrm{ppm}$. Of the 13 early responders in the treatment group, 7 (54\%) infants had a sustained response until 24 hours. However, the difference in the number of late responders, either sustained or delayed, between the two groups was not significant.

Baseline characteristics between infants treated with inhaled NO who showed an early response and non-responders are shown in table 4. Median birthweight, gestational age, incidence of PDA, pre-treatment with OI, and AT:RVET were similar in the two groups. Changes in AT:RVET with inhaled NO were also not significantly different between the groups. The proportion of deaths was greater in responders than in non-responders, and this may have reflected the tendency towards higher baseline risk score (which predicts the risk of CLD and death) in the former group.

The median dose of inhaled NO administered within the treatment period was $5 \mathrm{ppm}$ (range 5-20 ppm). One infant developed high concentrations of nitrogen dioxide $\left(\mathrm{NO}_{2}\right)$ (between 2.5 and $3 \mathrm{ppm}$ ); the dose of inhaled NO was therefore reduced to $5 \mathrm{ppm}$ despite the lack of an early response. Seven infants completed 72 hours of inhaled NO treatment and this was successfully withdrawn in all despite a small increase in oxygen requirements. Of the remaining 13 infants, four died and seven were extubated within 72 hours. In two inhaled NO was withdrawn following adverse events that may have been complications of treatment. One infant developed a pulmonary haemorrhage during inhaled NO treatment; although assessment of platelet function was not performed, and coagulation studies and platelet count were normal. The other infant developed clinically significant left to right shunting through a PDA (with an LA:Ao ratio $>1.5$ ). The incidence of sympto-

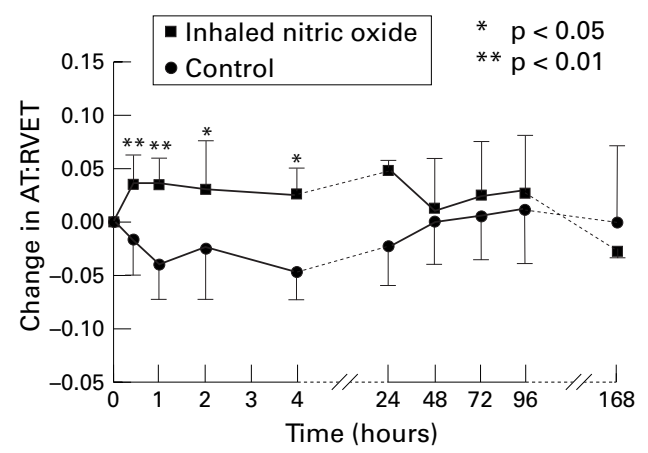

Data points represent medians (IQR)

Figure 3 Changes in AT:RVET with inhaled NO

matic PDA and pulmonary haemorrhage was similar in treated and control infants. ${ }^{17}$

ECHOCARDIOGRAPHIC FINDINGS

Serial echocardiographic examinations were performed in $41 / 42$ (98\%) infants. At entry to the trial, five treated and four control infants had a PDA. All of these infants had evidence of mild left to right ductal shunting (LA:Ao ratio $<1.5)$. No infant had significant interatrial right to left shunting. Assessment of PAP using the AT:RVET ratio was successful in 37/ $41(90 \%)$ infants. Ductal shunting with turbulent flow in the pulmonary artery prevented measurements being performed in the remainder.

The median baseline AT:RVET ratio was similar in treated infants and controls: $0.28 \mathrm{vs}$ $0.30(p=0.33)$ (table 2). Infants treated with inhaled NO rapidly responded, with a median rise in AT:RVET of 0.04 which was significantly different from controls within 30 minutes $(p<0.01)(f i g)$. The change in AT:RVET in the inhaled NO group was significantly different from the response seen in control infants until 4 hours. At 24 hours, there had been a median increase in AT:RVET of 0.05 in treated infants compared with a fall of 0.02 in controls $(p=0.11)$.

Further serial examinations were performed in a subset of 24 out of the $42(57 \%)$ infants enrolled into the main study. At trial entry some tricuspid regurgitation was identified in most infants, although only $11 / 24(46 \%)$ had a sufficiently strong signal which allowed peak velocity and systolic PAP to be measured. Two

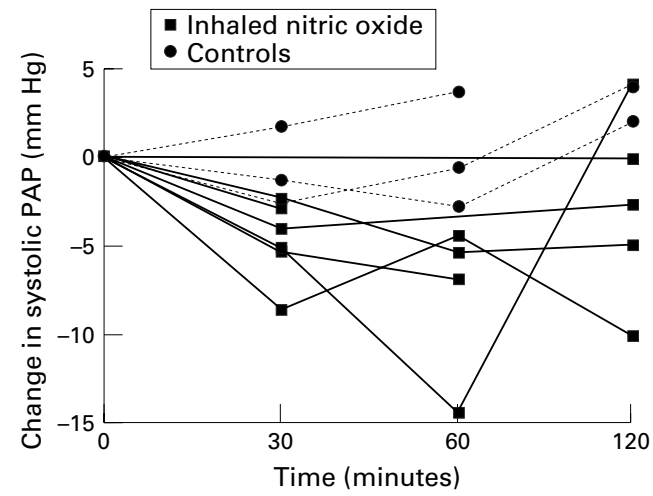

Figure 4 Individual changes in systolic PAP with inhaled $\mathrm{NO}$ 
Table 5 Changes in pulmonary haemodynamics with inhaled NO

\begin{tabular}{|c|c|c|c|c|c|c|c|c|}
\hline & \multicolumn{2}{|l|}{$s P A P$} & \multicolumn{2}{|l|}{ Change s PAP } & \multicolumn{2}{|l|}{$P A m d$} & \multicolumn{2}{|c|}{ Change PA md } \\
\hline & Treated & Control & Treated & Control & Treated & Control & Treated & Control \\
\hline 0 & $\begin{array}{l}40.7^{\star} \\
(31.3-47.6)\end{array}$ & $\begin{array}{l}29.8 \\
(24.5-34.9)\end{array}$ & & & $\begin{array}{l}1222 \\
(577-2000)\end{array}$ & $\begin{array}{l}1287 \\
(1089-1861)\end{array}$ & & \\
\hline 30 minutes & $\begin{array}{l}37.3 \\
(29.0-42.5)\end{array}$ & $\begin{array}{l}28.6 \\
(26.3-32.4)\end{array}$ & $\begin{array}{l}-4.6^{\star} \\
(-8.6--2.3)\end{array}$ & $\begin{array}{l}-1.2 \\
(-2.5-1.8)\end{array}$ & $\begin{array}{l}1261 \\
(484-1580)\end{array}$ & $\begin{array}{l}1236 \\
(996-1976)\end{array}$ & $\begin{array}{l}-98 \\
(-420-218)\end{array}$ & $\begin{array}{c}70 \\
(-290-232)\end{array}$ \\
\hline 1 hour & $\begin{array}{l}30.6 \\
(26.0-39.7)\end{array}$ & $\begin{array}{l}28.3 \\
(27.1-34.4)\end{array}$ & $\begin{array}{l}-6.1^{\star \star} \\
(-14.4--4.4)\end{array}$ & $\begin{array}{l}-0.5 \\
(-2.7-3.8)\end{array}$ & $\begin{array}{l}1259 \\
(469-1831)\end{array}$ & $\begin{array}{l}1122 \\
(968-1381)\end{array}$ & $\begin{array}{l}-80 \\
(-286-307)\end{array}$ & $\begin{array}{l}-131 \\
(-499--47)\end{array}$ \\
\hline 2 hours & $\begin{array}{l}35.8 \\
(26.5-51.8)\end{array}$ & $\begin{array}{l}35.5 \\
(30.3-43.8)\end{array}$ & $\begin{array}{l}-2.6 \\
(-10.0-4.2)\end{array}$ & $\begin{array}{c}3.1 \\
(2.1-4.1)\end{array}$ & $\begin{array}{l}1294 \\
(432-1715)\end{array}$ & $\begin{array}{l}1322 \\
(997-1641)\end{array}$ & $\begin{array}{l}-145 \\
(-284-385)\end{array}$ & $\begin{array}{l}-79 \\
(-301-149)\end{array}$ \\
\hline 4 hours & & & & & $\begin{array}{l}1389 \\
(718-1872)\end{array}$ & $\begin{array}{l}1413 \\
(974-1605)\end{array}$ & $\begin{array}{c}35 \\
(-224-419)\end{array}$ & $\begin{array}{l}-106 \\
(-339-171)\end{array}$ \\
\hline 24 hours & & & & & $\begin{array}{l}1466 \\
(994-1970)\end{array}$ & $\begin{array}{l}1478 \\
(1320-1712)\end{array}$ & $\begin{array}{l}237 \\
(46-564)\end{array}$ & $\begin{array}{c}129 \\
(-184-132)\end{array}$ \\
\hline
\end{tabular}

Values expressed as median (range).

$\mathrm{sPAP}=$ systolic pulmonary artery pressure $(\mathrm{mm} \mathrm{Hg}) ; \mathrm{PA} \mathrm{md}=$ pulmonary artery minute distance $(\mathrm{cm})$.

${ }^{\star} \mathrm{p}=0.04 ;{ }^{\star \star} \mathrm{p}=0.03$ vs control.

or more serial measurements of tricuspid regurgitation were possible in three control and nine treated infants within the first 24 hours. Baseline median systolic PAP was $40.7 \mathrm{~mm} \mathrm{Hg}$ in treated infants compared with $29.8 \mathrm{~mm} \mathrm{Hg}$ in controls $(p=0.04)$ (table 5). During the first 30 minutes the median change in systolic PAP of -4.6 (range -8.6 to -2.3 ) $\mathrm{mm} \mathrm{Hg}$ in infants treated with inhaled $\mathrm{NO}$ compared with -1.2 (range -2.5 to 1.8 ) $\mathrm{mm} \mathrm{Hg}$ in controls ( $\mathrm{p}=$ 0.04). Systolic PAP fell within 30 minutes in all treated infants and this was sustained in $3 / 4$ $(75 \%)$ infants in whom repeat measurement was possible at 2 hours (fig 4). After 2 hours there were too few infants with tricuspid regurgitation to justify further analysis.

Median pulmonary artery minute distance did not differ significantly between infants in the treatment and control groups (table 5). Although no overall differences was evident in changes in pulmonary artery minute distance with time, there was an inverse relation between changes in pulmonary artery minute distance and changes in OI within individuals treated with inhaled $\mathrm{NO}(\mathrm{r}=-0.43 ; \mathrm{p}<0.01)$. When infants with a PDA were excluded, pulmonary blood flow and OI were similarly related $(\mathrm{r}=-0.44 ; \mathrm{p}=0.01)$. There was no significant correlation between either pulmonary artery minute distance $(\mathrm{r}=0.24, \mathrm{p}=$ $0.14)$ or OI $(\mathrm{r}=-0.23, \mathrm{p}=0.07)$ with AT:RVET.

\section{Discussion}

This study was designed to study the effects of inhaled NO when used to improve gas exchange in an attempt to prevent CLD or death in a group of high risk preterm infants. We have shown that there is a short term improvement in both arterial oxygenation and PAP with inhaled NO treatment. However, these effects are transient and treatment did not influence long term outcome in this population. ${ }^{17}$

Previous studies in preterm animals have shown potential short term benefits with inhaled NO. ${ }^{25-27}$ In an experimental model of RDS, treatment with inhaled NO prevented the rise in pulmomonary vascular resistance and fall in pulmonary blood flow associated with prolonged mechanical ventilation, with an overall improvement in gas exchange. ${ }^{26}$
Inhaled nitric oxide treatment may also be beneficial in newborn infants, and several recent reports have described improved oxygenation in term and preterm infants. ${ }^{812-16}$ However, until now there have been no published randomised controlled trials showing its efficacy in preterm infants.

In this study treated infants responded rapidly, with a reduction in OI within $30 \mathrm{~min}$ utes of treatment. This response was sustained throughout the 72 hour period of inhaled NO treatment and until at least 24 hours following its withdrawal. Despite a decrease in OI in the group as a whole, the response to inhaled NO treatment varied widely among individuals. In one third of treated infants (non-responders), treatment either failed to have any effect, or infants had only a minimal response. In the remainder (responders) there was an improvement in oxygenation within 2 hours; about half of these had a sustained response for 24 hours. As the proportion of treated infants with a delayed response was not significantly greater than that of controls, our findings do not support the contention that the response to inhaled NO may be delayed in some infants. ${ }^{28}$

There were no identifiable factors that distinguished early responders from nonresponders. It has been suggested that the magnitude of the response to inhaled NO may be related to other factors such as the presence of pulmonary hypertension and extrapulmonary right to left shunting. ${ }^{8}{ }^{29}$ Although pulmonary hypertension is common in preterm infants with respiratory distress, we found no evidence of higher PAP in responders than non-responders. In addition, none of the infants in this study had Doppler echocardiographic evidence of clincally significant extrapulmonary shunting. We were therefore unable to assess its importance in influencing response.

The choice of a maximum initial dose of 20 ppm was based on previous studies in animals and human neonates. ${ }^{425}$ The dose of inhaled NO was weaned from $20 \mathrm{ppm}$ to $5 \mathrm{ppm}$ without a deterioration in oxygenation in all infants with an early response, suggesting that a lower starting dose might have been equally effective. The dose of inhaled NO required to achieve a response varies according to the parameter being studied: in adults the optimal dose for 
oxygenation is lower than that required to lower PAP. ${ }^{30}$ It could be argued that the use of higher doses in this study might have resulted in a greater proportion of responding infants. However, there is little published evidence supporting the use of higher doses in preterm infants. A previous study in infants with RDS found that $10 \mathrm{ppm}$ was more effective than 5 ppm, but no additional benefit with further increases to $40 \mathrm{ppm} .{ }^{31}$ As it was possible to withdraw successfully treatment in all infants with minimal rebound effects, dependence on inhaled NO is unlikely to be a major drawback of treatment in such infants. ${ }^{32}$

Inhaled nitric oxide had a rapid, although transient, effect on the pulmonary circulation with a significant reduction in PAP that was evident within 30 minutes of starting treatment. A pulmonary vasodilator effect with inhaled NO treatment has also been shown in animal studies, and in infants and older children with congenital heart disease. ${ }^{26} 33$ However, there are few published studies investigating changes in pulmonary haemodynamics with inhaled NO in children with respiratory disease. ${ }^{11}$

Several Doppler echocardiographic methods allow PAP to be assessed non-invasively. ${ }^{34}$ In this study PAP was principally assessed using the AT:RVET ratio because it enables almost all individuals to be studied successfully. The reduction in PAP with inhaled $\mathrm{NO}$ was confirmed in a subgroup of infants by estimating tricuspid regurgitation derived systolic PAP, although serial measurements were possible in less than half of infants studied using this method. The small number of infants with a PDA precluded the use of ductal flow velocities to assess PAP.

Unlike other vasodilators, inhaled $\mathrm{NO}$ is thought to act as a selective pulmonary vasodilator, thus allowing lowering of PAP without causing systemic hypotension. ${ }^{3}$ Our findings have confirmed the specific action of inhaled $\mathrm{NO}$ on the pulmonary circulation, because mean systemic arterial pressure was maintained despite successful lowering of PAP.

In infants with primary PPHN the improvement in oxygenation with inhaled $\mathrm{NO}$ is thought to occur through a reduction in pulmonary vascular resistance and a reversal of extrapulmonary shunting. ${ }^{4}$ In infants who have parenchymal lung disease without extrapulmonary shunting, it may also act by enhancing ventilation-perfusion matching (through a redistribution of pulmonary perfusion). ${ }^{89}$ The oxygenation response in infants in this study was weakly associated with increased pulmonary blood flow, but not with the reduction in PAP. The nature of this association is unclear: the improvement in oxygenation with inhaled NO treatment may have either been responsible for, or occurred in response to, an increase in total pulmonary blood flow. However, as with intravenous pulmonary vasodilators, any overall increase in global pulmonary blood flow without redistribution of pulmonary perfusion would merely further impair gas exchange by worsening ventilation-perfusion matching and/or intrapulmonary shunting. One explana- tion for the action of inhaled NO might be that it permits an increase in total pulmonary blood flow, but preferentially directs perfusion towards well ventilated areas of the lung. This in turn would enhance ventilation-perfusion matching and improve oxygenation. Conversely, the increased pulmonary blood flow may itself have resulted from a reduction in pulmonary vascular resistance through pulmonary vasodilation following improved arterial oxygenation..$^{35}$

Potential hazards of inhaled NO treatment include the buildup of toxic $\mathrm{NO}_{2}$, methaemoglobinaemia, and haemorrhagic complications related to altered platelet-endothelial interaction. ${ }^{36-38}$ We encountered few problems during this study, although one infant developed marginally high $\mathrm{NO}_{2}$ concentrations, and increased left to right ductal shunting was temporally associated with a pulmonary haemorrhage in another. In the latter, treatment with inhaled NO may have promoted excessive peripheral blood flow through the ductus, resulting in haemorrhagic pulmonary oedema. Although the importance of this observation requires further investigation, we would recommend caution when using inhaled NO to treat hypoxaemic respiratory failure in infants with PDA.

Our use of a scoring system allowed inhaled NO treatment to be restricted to a selected group at high risk of CLD, and prevented treatment in infants with a relatively good prognosis. The use of inhaled NO has previously been reserved for infants with severe respiratory failure. Increasingly, infants at risk of developing CLD are also being targeted in an attempt to minimise lung injury. The effectiveness of inhaled NO is likely to vary according to the underlying disease process and its severity. This study has shown a rapid improvement in oxygenation and reduction in PAP with inhaled $\mathrm{NO}$ in infants with a wide range of baseline disease severity.

In summary, we have confirmed, as part of a controlled study, that treatment with inhaled NO rapidly improves oxygenation and lowers PAP in preterm infants. Future studies will need to define possible mechanisms of action and address issues such as appropriate selection of infants for treatment, optimal dose, and identification of factors predicting response.

NVS was supported by the British Heart Foundation (R F Martin Junior Research Fellowship). This study was also Martin Junior Research Fellowship). This study was also supported by an equipment grant from the North West Regional
Health Authority Research and Development Executive, and Health Authority Research and Development Executive, and
Micro Medical Ltd, who supplied some of the gas monitoring Micro Medical Ltd, who supplied some of the gas monitoring
equipment. We also thank Dr J R Skinner for his helpful advice.

1 Mariani G, Barefield ES, Carlo WA. The role of nitric oxide in the treatment of neonatal pulmonary hypertension. Curr Op Pediatr 1996;8:118-25.

2 Kinsella JP, Abman SH. Recent developments in the pathophysiology and treatment of persistent pulmonary hypertension of the newborn. F Pediatr 1995;126:853-64.

3 Abman SH, Kinsella JP. Inhaled nitric oxide therapy of pulmonary hypertension and respiratory failure in premature and term neonates. Adv Pharmacol 1995;34:457-74.

4 Kinsella JP, Neish SR, Shaffer E, Abman SH. Low-dose inhalation nitric oxide in persistent pulmonary hypertension of the newborn. Lancet 1992;340:819-20.

5 Roberts JD, Polaner DM, Lang P, Zapol WM. Inhaled nitric oxide in persistent pulmonary hypertension of the newborn. Lancet 1992;340:818-9. 
6 Evans N. Shunts in patients with respiratory distress syndrome. Pediatrics 1993;92:737.

7 Evans NJ, Archer LN. Doppler assessment of pulmonary artery pressure and extrapulmonary shunting in the acute phase of hyaline membrane disease. Arch Dis Child 1991; 66:6-11

8 Rozé JC, Storme L, Zupan V, Morville P, Dinh Xuan AT Mercier JC. Echocardiographic investigation of inhaled nitric oxide in newborn babies with severe hypoxaemia. Lancet 1994; 344:303-5.

9 Rossaint R, Falke KJ, Lopez F, Slama K, Pison U, Zapol WM. Inhaled nitric oxide for the adult respiratory distress syndrome. N Engl f Med 1993;328:399-405.

10 Lonnqvist PA, Winberg P, Lundell B, Sellden H, Olsson GL. Inhaled nitric oxide in neonates and children with pulmonary hypertension. Acta Paediatr 1994;83:1132-6.

11 Abman SH, Griebel JL, Parker DK, Schmidt JM, Swanton $D$, Kinsella JP. Acute effects of inhaled nitric oxide in chil$\mathrm{D}$, Kinsella JP. Acute effects of inhaled nitric oxide in chil-
dren with severe hypoxemic respiratory failure. $\mathcal{F}$ Pediatr 1994;124:881-8.

12 Karamanoukian HL, Glick PL, Zayek M, et al. Inhaled nitric oxide in congenital hypoplasia of the lungs due to diaphragmatic hernia or oligohydramnios. Pediatric

13 Peliowski A, Finer NN, Etches PC, Tierney AJ, Ryan CA Inhaled nitric oxide for premature infants after prolonged rupture of the membranes. F Pediatr 1995;126:450-3.

14 Barefield ES, Karle VA, Philips JB, Carlo WA. Inhaled nitric oxide in term infants with hypoxaemic respiratory failure. fPediatr 1996;129:279-86.

15 The Neonatal Inhaled Nitric Oxide Study Group. Inhaled nitric oxide in full-term and nearly full-term infants with hypoxic respiratory failure. $N$ Engl 7 Med 1997;336:597604.

16 Roberts JD, Jr, Fineman JR, Morin FC 3rd, et al. Inhaled nitric oxide and persistent pulmonary hypertension of the nitric oxide and persistent pulmonary hyp.

17 Subhedar NV, Ryan SW, Shaw NJ. An open randomised controlled trial of inhaled nitric oxide and early dexam-
ethasone in high risk preterm infants. Arch Dis Child ethasone $\mathrm{F}$

18 Ryan SW, Nycyk J, Shaw NJ. Prediction of chronic neonatal lung disease on day 4 of life. Eur $\mathcal{F}$ Pediatr 1996;155:66871 .

19 Hallman M, Merritt TA, Jarvenpaa AL, et al. Exogenous human surfactant for treatment of severe respiratory distress syndrome: a randomized prospective clinical trial f Pediatr 1985;106:963-9.

20 Kosturakis D, Goldberg SJ, Allen HD, Loeber C. Doppler echocardiographic prediction of pulmonary arterial hyper1984;53:1110-5.

21 Iyer P, Evans N. Re-evaluation of the left atrial to aortic root ratio as a marker of patent ductus arteriosus. Arch Dis Child 1994;70:F112-7.
22 Yock PG, Popp RL. Noninvasive estimation of right ventricular systolic pressure by Doppler ultrasound in patients with tricuspid regurgitation. Circulation 1984; 70:657-62.

23 Skinner JR, Boys RJ, Heads A, Hey EN, Hunter S. Estimation of pulmonary arterial pressure in the newborn: study of the repeatability of four Doppler echocardiographic techniques. Pediatr Cardiol 1996;17:360-9.

24 Bland JM, Altman DG. Calculating correlation coefficient with repeated observations:- correlation within subjects. $B M F$ 1995;310:446

25 Kinsella JP, McQueston JA, Rosenberg AA, Abman SH. Hemodynamic effects of exogenous nitric oxide in ovine transitional pulmonary circulation. Am f Physiol 1992; 263: H875-80.

26 Kinsella JP, Ivy DD, Abman SH. Inhaled nitric oxide improves gas exchange and lowers pulmonary vascular resistance in severe experimental hyaline membrane disease. Pediatr Res 1994;36:402-8.

27 Skimming JW, DeMarco VG, Cassin S. The effects of nitric oxide inhalation on the pulmonary circulation of preterm lambs. Pediatr Res 1995;37:35-40.

28 Abman SH, Kinsella JP. Inhaled nitric oxide for persistent pulmonary hypertension of the newborn: the physiology

29 Finer NN, Etches PC, Kamstra B, Tierney AJ, Peliowski A, Ryan CA. Inhaled nitric oxide in infants referred for extracorporeal membrane oxygenation: dose response. F Pediatr 1994;124:302-8.

30 Gerlach H, Rossaint R, Pappert D, Falke KJ. Time-course and dose response of nitric oxide inhalation for systemic oxygenation and pulmonary hypertension in patients with adult respiratory distress syndrome. Eur f Clin Invest 1993;23:499-502

31 Mupanemunda RH, Silverman M. Inhaled nitric oxide in respiratory distress syndrome. Pediatr Res 1994;35:346A

32 Miller OI, Tang SF, Keech A, Celermajer DS. Rebound pulmonary hypertension on withdrawal from inhaled pulmonary hypertension on with

33 Roberts JD, Jr., Lang P, Bigatello LM, Vlahakes GJ, Zapol WM. Inhaled nitric oxide in congenital heart disease. CirWM. Inhaled nitric oxid

34 Zellers T, Gutgesell HP. Noninvasive estimation of pulmonary artery pressure. $\mathcal{F}$ Pediatr $1989 ; 114: 735-41$

35 Fineman JR, Soifer SJ, Heymann MA. Regulation of pulmonary vascular tone in the perinatal period. Anпu Rev Physiol 1995;57:115-34.

36 Foubert L, Fleming B, Latimer R, et al. Safety guidelines for use of nitric oxide. Lancet 1992;339:1615-6.

37 Heal CA, Spencer SA. Methaemoglobinaemia with high-dose nitric oxide administration. Acta Paediatr 1995; 84:1318-9.

38 Hogman M, Frostell C, Arnberg H, Sandhagen B, Hedenstierna G. Bleeding time prolongation and NO inhalation. Lancet 1993;341:1664-5. 